\title{
Assessing the Availability and Application of E-Learning Resources in Schools of Midwifery in Anambra State
}

\author{
Obiageli Ifeoma Ikwuka ${ }^{1}$, Helen Simon Nwafor ${ }^{2}$, Christiana Ebele Dike ${ }^{2}$, Lydia Ijeoma Eleje ${ }^{1}$, Theresa Nkiru \\ Uzor $^{3}$, David Chibuike Ikwuka** \\ ${ }^{1}$ Department of Educational Foundations, Nnamdi Azikiwe University \\ Awka, Nigeria \\ ${ }^{2}$ School of Midwifery, Chukwuemeka Odimegwu Ojukwu Teaching Hospital \\ Nkpor, Anambra State, Nigeria \\ ${ }^{3}$ Department of Human Kinetics and Health Education, Nnamdi Azikiwe University \\ Awka, Nigeria \\ ${ }^{4}$ Department of Human Physiology, Nnamdi Azikiwe University Nnewi Campus \\ Nnewi, Nigeria \\ *Corresponding author's email: dc.ikwuka [AT] unizik.edu.ng
}

\begin{abstract}
This study assessed theavailability and application of e-learning resources in schools of midwifery in Anambra State. This descriptive survey design study was guided by two research questions. 88 midwife tutors in the five schools of Midwifery in Anambra State made-up the population. The sample is the same as the population as the population is of manageable size. Checklist was used to obtain data and the data were analyzed using frequencies and percentages. The validation of the instrument was done by three specialists. Cronbach alpha method was used to test the reliability and the alpha coefficients of 0.73 and 0.75 respectively were gotten for sections $A$ and $B$. The findings revealed that few e-learning resources were available and utilized in schools of midwifery in Anambra State. The implications of the study were highlighted and it was recommended that government should organize seminars and workshops to train nurse tutors on the usage of e-resources to improve learning in nursing schools. Also suggestions for further studies were made.
\end{abstract}

Keywords--- Midwifery, E-learning, ICT, Midwife tutors, Resources

\section{INTRODUCTION}

Rapid growth in Information and Communication Technologies (ICT) has changed the way we live, work and learn. In higher education, e-learning (the use of ICT for teaching and learning) has been promoted as a method for developing a workforce able to contribute to the digital and knowledge-based economy (Eleje et.al, 2019). Similarly, in healthcare, e-learning has been endorsed as a tool for developing essential skills and a way to facilitate life-long professional development (Beasley, 2009).The push for technology is also apparent in healthcare education where elearning has been described as a revolution in education for healthcare professionals (Ruiz et al., 2006). E-learning is defined as a solitary/individual or collaborative/group activity involving synchronous (happening in "real time", with all participants online at the same time) or asynchronous (with flexible choices of study time) communication processes (Romiszowsk, 2013). E-learning addresses a broad set of processes and applications such as web-based and computerbased teaching, using virtual classrooms and digital collaboration (Ikwuka et.al, 2020). It also includes delivering content through the internet, intranet/extranet, audio, video and radio recordings, through satellite, interactive TV, and CD-ROM. Thus, e-learning is interactive and offers instructional flexibility (Appiagyei et al., 2015). Indeed, one of the most common claims made of e-learning has been its potential for developing what has been a coined 21st skill (Bradwell, 2009). These skills are argued as essential for all graduates entering the Knowledge Economy (KE), and include digital literacy, creativity, flexibility and adaptability (Comrie, 2007). Comrie added that when used appropriately, e-learning has been purported to enable deeper learning; develop learner autonomy; increase participation, collaboration and interaction in the classroom; and provide students with a more active role in their learning.

E-learning is being introduced globally into midwifery training institution with an accompanying demand for computer literacy for both students and educators (Button, 2014). While and Dewsbury (2011), argue that midwives need 
to be competent in informatics in their clinical practice. While and Dewsbury (2011)also suggested that the midwifery workforce needs to have ICT skills in order to be the electronic systems managers which the profession increasingly requires. It is therefore important that midwifery training includes ICT skills as an integral part of the learning experience as well as the core skills necessary to access modern learning resources. Midwife educators need to ensure that student midwives have ICT literacy, and the adoption of e-learning and classroom based information technology is an important step toward this.In midwifery education, e-learning has been portrayed as supporting self-directed learning, promoting the acquisition of ICT skills and encouraging the transition from classroom to independent lifelong learning (Thiele, 2003). Elearning has also been promoted as a tool that can create greater motivation to learner compared with traditional lectures (Woo \&Kimmick, 2000); enhance critical and reflective skills (Ali, 2012); and lead to greater student satisfaction (Maag, 2004).The development of e-learning and computer competence has not only been promoted as a means for developing $21^{\text {st }}$ century skills but also as a method for encouraging midwifery professionals to become more involved in the development of technology (Willmer,2005). E-learning also facilitates effective clinical skills acquisition in a safe environment and enhances face-to-face learning, asynchronous communication with staff and study groups, and contributes to in-classroom interaction and record keeping (Bloomfield \& Jones, 2013).

E-learning has been argued to directly challenge some of the critical assumptions on which midwifery schools were founded, thus questioning years of didactic approaches to teaching (Schnekenberg, 2009). An academic who believes that face-to-face instruction in the traditional classroom is the best way for students to learn will design their teaching accordingly (Meyer, 2012). For example, Steel and Hudson (2011) observed that a number of the midwifery school teachers they interviewed considered face-to-face, didactic teaching as the most crucial element in all pedagogic processes. Fanghanel (2007) contends that pedagogical stance has a powerful influence on e-learning adoption in teaching and learning experiences. According to this Fanghanel, pedagogical stance is defined as choices and interventions made within a learning environment and are developed from prior learning experiences which are often taken for granted. Hence, it follows that a midwifery school tutor's choice to use technology will depend on how much it fits with what they see as the best way for students to learn (Jaffee, 2003).The utilization of e-learning offers greater flexibility regarding time and location of teaching and learning (Bloomfield \& Jones, 2013).It can provide greater flexibility to adapt teaching and learning to meet the learner's cognitive and learning styles. It enhances the quality of learning where its use is tailored to lesson objectives and the need of the learners. Midwives are prepared to be accountable for their own practice, accept responsibility for provision of care to others and work with others. The use of e-learning is relevant and functional in providing them the education that will assist in imbibing in them the required capacity for the world of work needed in this practice. For example if a student is able to observe live procedure (realia) using e-learning resources (U-tube), during practice the person will be able to perform better compared to someone that learned through face-to-face, didactic teaching.

The availability and utilization of e-learning in midwifery schools has been slow. Yet, to continue contributing to meeting learning objectives, midwife educators must utilize e-learning in their teaching processes. The utilization can help in higher efficiency, higher productivity, and higher educational outcomes including quality of cognitive, creative and innovative outcomes. It will also contribute to increase in the interaction and reception of information, provide them the ability to evaluate current practices and try new approaches and be able to contribute to client care during practice. Ebersole and Vorndam (2003) have suggested that the first step to successful e-learning utilization is the removal of barriers and the presence of incentives. The incentives will motivate the tutors to undergo the necessary training that they need in order to effectively and efficiently utilize e-learning resources in teaching and learning, thereby changing the way that student midwives lives, learn and study.

The use of e-learning resources in guiding patients to relevant sources of health information and faster retrieval of information from the internet, requires that midwife staff should have skills to use computers, positive attitudes to new technologies, and as well as accept the utilization of new technology in daily practices. Specifically motivated by a desire to address the failure rate in midwifery licensing examinations and reduced number of students being admitted in schools of midwifery as a result of limited facilities, the use of e-learning resources was chosen as an intervention to supplement and reinforce lessons learned in the schools of midwifery and also increase the number of students admitted in accordance with the rules made by Nursing and Midwifery Council of Nigeria on number of students to be admitted.

Despite the enthusiasm noted in the government discourse and the decree endorsing the use of e-learning resources in schools, many academics have been slow to integrate e-learning into their teaching (beyond the didactic use of PowerPoint). Pro-technology advocates have expounded that many in schools of midwifery have resisted e-learning because they have been trapped in a vision of the traditional university; a vision originating from a long established convention of being state funded and controlled, while still maintaining significant autonomy (Schneckenberg, 2009). It is against this background that the researchers investigated the availability and utilization of e-learning resources in schools of midwifery in Anambra State.

\section{RESEARCH QUESTIONS}

1. What are the e-learning resources available in schools of midwifery in Anambra State?

2. What are the e-learning resources utilized in schools of midwifery in Anambra State? 


\section{METHOD}

\section{Research Design, Setting and Population}

The study employed survey design to seek the opinion of teachers and students on feasibility of utilizing e-learning approach in teaching students in schools of midwifery in Anambra State. This survey study was conducted in Anambra State, Nigeria. The population for the study comprised 88 tutors in the five Schools of Midwifery in Anambra State. The entire population was used as the sample for the study because the population is of manageable size.

\section{Research Instruments}

The instruments used to collect data were two sets of checklist titled "Availability of E-learning Resources in Schools of Midwifery (AERSM)" and "Utilization of E-learning Resources in Schools of Midwifery (UERSM)". The instruments were developed by the researchers and guided by the research questions for the study. AERSM sought to ascertain the e-learning resources that were available in various schools of midwifery and has 10 items. It was structured on a two-point rating scale of Available (A) and Not Available (NA).UERSM sought to ascertain the utilization of elearning resources in schools of midwifery and has 10 items. It was also structured on a two-point rating scale of Utilized (U) and Not Utilized (NU). The instruments were validated by three expert validators in instrument construction. The instrument reliability was tested using Cronbach alpha method and alpha coefficient 0.73 and 0.75 respectively for section $\mathrm{A}$ and $\mathrm{B}$ were gotten. These values were adjudged adequate and the instrument reliable.

\section{Research Procedure for Data Collection and Analysis}

In the administration of this instrument, the researchers with three research assistants obtained permission from the relevant authorities in the selected schools and distributed copies of the questionnaire to the tutors in the five schools of midwifery. The questionnaires were filled in accordance with the instructions given by the researchers, and were collected after they have been completed. The researchers adopted the Direct Delivery Method (DDM) to administer copies of the questionnaires to the respondents.

\section{Method of Data Analysis}

Frequencies and percentages were used to analyze the data collected. The decision rule is that any percentage score of 50 and above is taken as available or utilized, while percentage scores below 50 is taken as not available or not utilized.

\section{RESULTS}

In this section is presented the analysis of data collected in the study. The presentation and analysis were done in line with the research questions.

Research Question One: What are the e-learning resources available in schools of midwifery in Anambra State?

Table 1: Frequencies and Percentages of Availability of E-learning Resources in Schools of Midwifery (N=88).

\begin{tabular}{lllll}
\hline S/N & Items & Freq. & \% & Decision \\
\hline 1. & Computer: laptop, palmtop and pocket computers & 34 & 38.6 & NA \\
2. & Educational robots & 41 & 46.6 & NA \\
3. & Teleconferencing devices & 36 & 40.9 & NA \\
4. & Overhead projector & 72 & 81.8 & A \\
5. & Digital photocopier & 79 & 89.8 & A \\
6. & Internet browser & 38 & 43.2 & NA \\
7. & Flash memories and slides & 69 & 78.4 & A \\
8. & Multi-media projector & 37 & 42.0 & NA \\
9. & E-readers and e-books & 30 & 34.1 & NA \\
10. & E-graphics board for sketches and diagrams & 21 & 23.9 & NA \\
\hline
\end{tabular}

Data in Table 1 shows that few e-learning resources (overhead projector, digital photocopier, flash memories and slides) are available in schools of midwifery as indicated by the respondents. The respondents also indicated that majority of the e-learning resources not available in schools of midwifery such as computer, educational robots, teleconferencing devices, internet browser, multi-media projector, e-readers and e-books and e-graphics board for sketches and diagrams because less than $50 \%$ of schools reported having them. 
Research Question Two: What are the e-learning resources utilized in schools of midwifery in Anambra State?

Table 2: Frequencies and Percentages of Utilization of E-learning Resources in Schools of Midwifery (N=88).

\begin{tabular}{lllll}
\hline S/N & Items & Freq. & \% & Decision \\
\hline 1. & Computer: laptop, palmtop and pocket computers & 28 & 31.8 & NU \\
2. & Educational robots & 25 & 28.4 & NU \\
3. & Teleconferencing devices & 26 & 29.5 & NU \\
4. & Overhead projector & 57 & 64.8 & $\mathrm{U}$ \\
5. & Digital photocopier & 59 & 67.0 & $\mathrm{U}$ \\
6. & Internet browser & 23 & 26.1 & $\mathrm{NU}$ \\
7. & Flash memories and slides & 49 & 55.7 & $\mathrm{U}$ \\
8. & Multi-media projector & 24 & 27.3 & $\mathrm{NU}$ \\
9. & E-readers and e-books & 16 & 18.2 & $\mathrm{NU}$ \\
10. & E-graphics board for sketches and diagrams & 20 & 22.7 & $\mathrm{NU}$ \\
\hline
\end{tabular}

Data in Table 2 shows that few e-learning resources (overhead projector, digital photocopier and flash memories and slides) are utilized in schools of midwifery as indicated by the respondents. The respondents also indicated that majority of the e-learning resources not utilized in schools of midwifery such as computer, educational robots, teleconferencing devices, internet browser, multi-media projector, e-readers and e-books and e-graphics board for sketches and diagrams because less than $50 \%$ of schools reported not utilizing them.

\section{DISCUSSION}

\section{Availability of E-Learning Resources in Schools of Midwifery in Anambra State}

The findings of the study revealed that while few e-learning resources such as overhead projector, digital photocopier and flash memories and slides are available in the schools of midwifery, majority of the e-learning resources are not available in schools of midwifery such as computer, educational robots, teleconferencing devices, internet browser, multi-media projector, e-readers and e-books and e-graphics board for sketches and diagrams. The findings of the study agree with the assertion of Sivasubramaniyan and Batcha(2012) that availability will be as good as the resources which can be afforded with number of computers and existence of network systems, the ability to work with tools, and the network infrastructure that supports rapid and convenient connections. The findings of the study are consistent with the findings of Hartley (2007) that majority of the new technologies needed by teachers in teaching-learning situations are not available. The findings of this study are also in tandem with Leach (2008) who posited that the new e-learning resources needed for achieving the goals of education for all are not available. The findings of the study further tally with Nwana (2012) that the new technologies for effective ICT implementation in schools were not available.

\section{Utilization of E-Learning Resources in Schools of Midwifery in Anambra State}

The findings of the study revealed that while few e-learning resources such as overhead projector, digital photocopier and flash memories and slides are utilized in the schools of midwifery, majority of the e-learning resources are not utilized in schools of midwifery such as computer, educational robots, teleconferencing devices, internet browser, multi-media projector, e-readers and e-books and e-graphics board for sketches and diagrams. The findings of the study agree with Moule (2010) when he posited that most educators were found to be using technology for basic administrative purposes such as for email and creating lecture notes, but had not exploited the full potential of technology. Moule added that only a small number of staff surveyed was using discussion boards and social networking tools, with the majority of educators using the Virtual Learning Environment (VLE) as a repository for information. The findings of the study also agree with (Kiekkas, 2006) when he noted that E-learning is felt to be useful when it streamlines midwifery processes, makes procedures more accurate and reduces the risk of human error. Kiekkas however argued that midwives may experience that the use of technical equipment increase stress and decreases autonomy. The findings of the study also agree with Lefuma (2017) that the ability to use e-resources efficiently depends on the basis of computer skills, knowledge of what is accessible and how to use it.

\section{CONCLUSION}

Based on the findings of the study, it was concluded that few e-learning resources are available in schools of midwifery in Anambra State. The researchers also concluded that few e-learning resources are utilized in schools of midwifery in Anambra State. 


\section{Implications of Findings}

The following are implications of findings:

The findings of the study revealed that computer, educational robots, teleconferencing devices, internet browser, multimedia projector, e-readers and e-books and e-graphics board for sketches and diagrams are not available in schools of midwifery. This implies that instructional delivery in schools of midwifery will remain cumbersome without the availability of e-learning resources such as computer, educational robots, teleconferencing devices, internet browser, multi-media projector, e-readers and e-books and e-graphics board for sketches and diagrams.

The findings of the study revealed that computer, educational robots, teleconferencing devices, internet browser, multi-media projector, e-readers and e-books and e-graphics board for sketches and diagrams are not utilized in schools of midwifery. This implies that effective teaching and learning will remain a mirage in schools of midwifery without the utilization of e-learning resources such as computer, educational robots, teleconferencing devices, internet browser, multimedia projector, e-readers and e-books and e-graphics board for sketches and diagrams.

\section{RECOMMENDATIONS}

Based on the findings of the study, the following recommendations were made:

1. Anambra State government should provide support to schools of midwifery so they may obtain recommended Internet connectivity, acquire generators to serve as backup when electricity is limited, purchase and install antivirus software and computers for labs.

2. School administrators should expand upon the training of server administration, student enrollment to the platform, and general implementation management.

3. The policy makers should develop national guidelines on how to make available e-learning resources that support the standards taught in schools of midwifery in Nigeria.

4. The government should ensure the institutionalization of e-learning systems to improve midwifery performance.

5. Government should organize seminars and workshop to train nurse tutors on the utilization of e-learning resources for effective teaching and learning in schools of nursing.

6. School administrators should make available infrastructural facilities such as the computer laboratory and computerized laboratory in schools of midwifery for effective instructional delivery.

\section{REFERENCES}

Ali, N. S., Hodson-Carlton, K., \& Ryan, M. (2002). Web-based professional education for advanced practice nursing: a consumer guide for program selection. Journal of continuing education in nursing, 33(1), 3338.https://pubmed.ncbi.nlm.nih.gov/15887358/

Appiagyei, M., Trump, A., Danso, E., Yeboah, A., Searle, S., \& Carr, C. (2015). Case Study: The Role of eLearning in Midwifery Pre-Service Education in Ghana. World health \& population, 16(2), 54-61. https://doi.org/10.12927/whp.2016.24492

Beasley, C. (2009, March 31). The Chief Nursing Officer's action plan for the profession. Nursing Times https://www.nursingtimes.net/archive/the-chief-nursing-officers-action-plan-for-the-profession-31-03-2009/

Bloomfield, J. G., \& Jones, A. (2013). Using e-learning to support clinical skills acquisition: exploring the experiences and perceptions of graduate first-year pre-registration nursing students - a mixed method study. Nurse education today, 33(12), 1605-1611. https://doi.org/10.1016/j.nedt.2013.01.024

Bradwell, P. (2009). The edgeless university: Why higher education must embrace technology.Demos.https://dera.ioe.ac.uk/23211/1/Edgeless_University___web.pdf

Button, D., Harrington, A., \&Belan, I. (2014). E-learning \& information communication technology (ICT) in nursing education: A review of the literature. Nurse education today,34(10), 1311-1323. https://doi.org/10.1016/j.nedt.2013.05.002

Comrie, A. K. (2007).Transforming and enhancing the student experience through pedagogy. In: JISC.Scottish Funding Council e-Learning TransformationProgramme.https://www.yumpu.com/en/document/read/23670163/teseptransforming-and-enhancing-the-student-experience-jisc

Ebersole, S. \&Vorndam, M. (2003). Adoption of computer-based instructional methodologies: A case study. International Journal on E-learning, 2 (1),15-20. 
Eleje, L.I., Esomonu, N.P.M., \& Ufearo, F.N. (2019). Trends in information and communication technology and learning assessment: The application and implication. International Educational Applied Research Journal (IEARJ), 3(11): 1-6. Retrieved from http://iearj.com/archive-sub.php?

Fanghanel, J. (2007). Investigating university lecturer's pedagogical constructs in the working context. Report on Research Project for the Higher Education Academy (HEA). London, HEA.https://s3.eu-west2.amazonaws.com/assets.creode.advancehe-documentmanager/documents/hea/private/fanghanel 1568036793.pdf

Hartley, J. (2007), Teaching, learning and new technology: a review for teachers. British Journal of Educational Technology, 38: 42-62. https://doi.org/10.1111/j.1467-8535.2006.00634.x

Ikwuka, O. I., Onyali, L. C., Olugbemi, O. P., Etodike, C. E., Igbokwe, I. C., \& Adigwe, E. J. (2020). Teachers' attitude towards the use of ICT for quality instructional delivery in Onitsha North secondary schools, Anambra State, Nigeria. International Journal of Academic Research in Progressive Education \& Development, 9(3), 1-11. DOI:10.6007/IJARPED/v9-i3/7980

Jaffee, D. (2003). Virtual transformation: Web-based technology and pedagogical change. Teaching Sociology, 31 (2), $227-$ 236.

Kiekkas, P., Karga, M., Poulopoulou, M., Karpouhtsi, I., Papadoulas, V., \&Koutsojannis, C. (2006). Use of technological equipment in critical care units: nurses' perceptions in Greece. Journal of Clinical Nursing, 15(2), $178-187$. https://doi.org/10.1111/j.1365-2702.2006.01243.x

Kim, D., \& Chang, H. (2007). Key functional characteristics in designing and operating health information websites for user satisfaction: an application of the extended technology acceptance model. International Journal of Medical Informatics, 76(11-12), 790-800. https://doi.org/10.1016/j.ijmedinf.2006.09.001

Leach, J. (2008). Do new information and communication technologies have a role to play in the achievement of education for all? British Educational Research Journal, 34 (6), 783-80.https://www.jstor.org/stable/40375541

Lefuma, S. (2017). Access to and use of electronic information resources in the academic libraries of the Lesotho library consortium[Unpublished Doctoral dissertation] University of KwaZulu-Natal.http://hdl.handle.net/10413/14345

Maag M. (2004). The effectiveness of an interactive multimedia learning tool on nursing students' math knowledge and self-efficacy. Computers, Informatics, Nursing: CIN, 22(1), 26-33. https://doi.org/10.1097/00024665$\underline{200401000-00007}$

Meyer, K. A. (2012). Quality in distance education: Focus on on-line learning.JosseyBass.https://files.eric.ed.gov/fulltext/ED470042.pdf

Moule, P., Ward, R. and Lockyer, L. (2010). Issues with e-learning in nursing and health education in the UK: Are new technologies being embraced in the teaching and learning environments? Journal of Research in Nursing, 1 (1), 34-37.

Nwana, S.E. (2012). Challenges in the application of e-learning by secondary school teachers in Anambra State, Nigeria. African Journal of Teacher Education (AJOTE), 2 (1), 14-22.https://doi.org/10.21083/ajote.v2i1.1913

Ruiz, J. G., Mintzer, M. J., \& Leipzig, R. M. (2006). The impact of E-learning in medical education. Academic medicine: Journal of the Association of American Medical Colleges, 81(3), 207-212. https://doi.org/10.1097/00001888200603000-00002

Schneckenberg, D. (2009). Understanding the real barriers to technology-enhanced innovation in higher education. Educational Research, 51 (1),411-424.https://doi.org/10.1080/00131880903354741

Steel, J. \& Hudson, A. (2011). Educational technology in learning and teaching: The perceptions and experience of teaching staff. Innovations in Education and Teaching International, 38 (1),103111.https://doi.org/10.1080/13558000010030158

Thiele, J. E. (2003). Learning patterns of online students. TheJournal of Nursing Education, 42 (1),364-366.

While, A., \& Dewsbury, G. (2011). Nursing and information and communication technology (ICT): a discussion of trends and future directions. International Journal of Nursing Studies, 48(10), 1302-1310. $\underline{\text { https://doi.org/10.1016/j.ijnurstu.2011.02.020 }}$ 
Willmer, M. (2005). Promoting practical clinical management learning: The current situation about Information and Communications Technology capability development in student nurses. Journal of Nursing Management, 13 (1),467-476.https://doi.org/10.1111/j.1365-2934.2005.00603.x

Woo, M. A., \&Kimmick, J. V. (2000). Comparison of Internet versus lecture instructional methods for teaching nursing research. Journal of Professional Nursing: Official journal of the American Association of Colleges of Nursing, 16(3), 132-139. https://doi.org/10.1053/PN.2000.5919 